\title{
Spectrofluorimetric Determination of Alendronate by Conjugation with the Rhodamine B Sulfonyl Group
}

\author{
Yunseong Jeong, Jihye Park, Geun-woo Jin, and Jong-Sang Park* \\ Department of Chemistry, College of Natural Science, Seoul National University, Seoul 151-742, Korea \\ *E-mail: pfjspark@plaza.snu.ac.kr \\ Received January 3, 2011, Accepted March 9, 2011
}

Key Words : Alendronate, Rhodamine B sulfonyl chloride, Spectrofluorometer, Fluorescence, Bisphophonate

Alendronate, one of the bisphosphonate group of drugs, is used in the treatment of bone metastasis and several bone disorders, such as Paget's disease and osteoporosis, in postmenopausal women and older people. ${ }^{1,2}$ Generally, because the concentrations of alendronate in the therapeutic range are very low for intravenous and transdermal administration, its quantitative estimation is quite difficult. Therefore, a sensitive and simple method for determining alendronate concentration in patients' blood is required for medical and clinical purposes; to this end, a number of researchers have attempted to develop various sensitive analytical methods. ${ }^{3-8}$ $\mathrm{NadDPA}-2 \mathrm{Zn}^{2+}$, a fluorescent chemosensor (FCS), which is used for the recognition of certain molecules or ions, was identified as a new analytical tool for the determination of alendronate in our previous study. ${ }^{9}$ However, analysis using NadDPA- $2 \mathrm{Zn}^{2+}$ is not very effective as a method because of its low sensitivity (limit of quantitation $(\mathrm{LOQ})=0.104 \mu \mathrm{g} /$ $\mathrm{mL}$ ), due to the fact that fluorescent activity of the naphth- alzene group, which act as a chromophore in NadDPA$2 \mathrm{Zn}^{2+}$, is not high; the molar extinction coefficient $(\varepsilon)$ is $6,000 \mathrm{M}^{-1} \mathrm{~cm}^{-1}$ at $275 \mathrm{~nm}^{.11}$

Rhodamine B sulfonyl chloride (RBSC, Fig. 1(a)) is a typical dye used as a conjugation agent in the analysis of primary amines by UV-visible and fluorescence spectroscopy. ${ }^{10}$ Similarly, the conjugation of the 9-fluorenylmethyoxycarbonyl (Fmoc) group with the primary amine in alendronate is exploited in high-performance liquid chromatography (HPLC). ${ }^{13}$ The extinction coefficient of RBSC $(\varepsilon=$ $100,000 \mathrm{M}^{-1} \mathrm{~cm}^{-1}$ at $\left.556 \mathrm{~nm}\right)$ is much higher than that of Fmoc $\left(\varepsilon=7,800 \mathrm{M}^{-1} \mathrm{~cm}^{-1}\right.$ at $\left.266 \mathrm{~nm}\right)$.

We assumed that, if a molecule includes a better active fluorescent chromophore structure in a biological solution such as blood, serum, urine or plasma, the chemical can be easily and simply detected by UV-vis. or fluorescence spectrophotometers, after pretreatment of a crude sample without needing to the follow a method involving

(a)<smiles>CCN(CC)c1ccc2c(-c3ccc(S(=O)(=O)Cl)cc3S(=O)(=O)[O-])c3ccc(=[N+](CC)CC)cc-3oc2c1</smiles>

Rhodamine B sulfonyl chloride

(b)

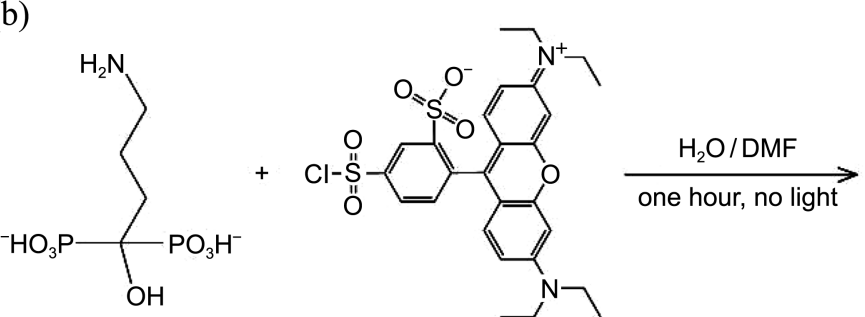

Alendronate

Rhodamine B sulfonyl chloride

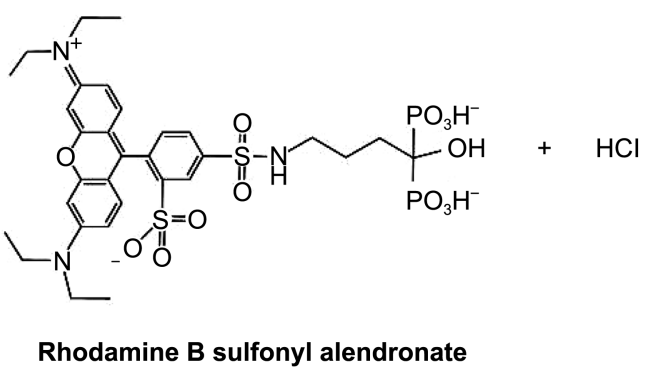

Figure 1. (a) Structure of rhodamine B sulfonyl chloride (RBSC) and its value of extinction coefficient (b) The synthetic scheme of rhodamine B sulfonyl alendronate (RBSA) from alendronate and RBSC. 
chromatography. We found that spectrofluorimetric determination by conjugation with RBSC was a more useful and sensitive tool for the analysis of alendronate than conjugation with the fluorescent chemosensor (FCS) NadDPA- $2 \mathrm{Zn}^{2+}$.

\section{Experimental Section}

Materials and Instruments. Alendronate (sodium salt) was purchased from Langfang Shinya Chemical Co., Ltd. (China) and 2-[4-(2-hydroxyethyl)-1-piperazinyl]-ethane sulfonic acid (HEPES) buffer solution (pH 7.0-7.5; $1 \mathrm{M}$ in water), $0.5 \mathrm{M}$ EDTA-Na $(\mathrm{aq})$, methylene chloride, dimethylformamide (DMF, 99\%), tetrachloroacetic acid (TCA), sodium hydroxide (powder), sodium carbonate, bicarbonate, and calcium chloride were obtained from Sigma-Aldrich (USA). Fluorescence detection was performed using a spectrofluorometer (FT-650; Jasco, Japan), and all samples were dispensed in cuvettes (No. 1916, Italy). The ${ }^{1} \mathrm{H}$ NMR (Bruker, Avance 300, $300 \mathrm{MHz}, 11.4$ Tesla) was utilized to confirm a product. Male SpragueDawley rats (age, 7-8 weeks; weight, 180-200 g) were used in this study.

LOD/LOQ Test. In order to achieve a calibration curve and confirm its linearity, and the LOD/LOQ (limit of detection/quantitation) of this method, alendronate/buffer (sodium carbonate/bicarbonate, $\mathrm{pH} 9 ; 0.1 \mathrm{M}$ ) solutions were prepared as standards in the concentration range of $0.1-150 \mathrm{ng} / \mathrm{mL}$. RBSC was dissolved in DMF at a concentration of $2 \mathrm{mg} / \mathrm{mL}$ under protection from light. RBSC/DMF solutions ( $1 \mathrm{~mL}$ ) was slowly added to $1 \mathrm{~mL}$ of each of the standard solutions by gently mixing in the dark; this was followed by stirring for $1 \mathrm{~h}$ at room temperature in the dark. Subsequently, the conjugation reaction between alendronate and RBS occurred (Fig. 1(b)). Excess RBSC and DMF in the mixture were removed by extraction three times with $3 \mathrm{~mL}$ of methylene chloride through the elimination of organic phase. $\mathrm{CaCl}_{2}$ (aq) $(0.5 \mathrm{~mL} ; 1.25 \mathrm{M})$ was added to the water phase to induce precipitation of calcium rhodamine B sulfonyl alendronate (s). After centrifugation for $10 \mathrm{~min}$ at $6,300 \times g$, the precipitate was washed with $1 \mathrm{~mL}$ of distilled water three times. Finally, the washed precipitate was dissolved in $1 \mathrm{~mL}$ of $1 \mathrm{M}$ $\mathrm{HCl}(\mathrm{aq})$. This final solution was analyzed using a spectrofluorometer after it was transferred to a transparent cuvette. The final product, rhodamine B sulfonyl alendronate (RBSA) was also confirmed by nuclear magnetic

Table 1. Linearity, range, LOD, and LOQ. The equations of the calibration curve were obtained from 18 points. LOD and LOQ were defined as the concentrations of at $3 \times \mathrm{S} / \mathrm{N}$ and $10 \times \mathrm{S} / \mathrm{N}$ ratios, respectively

\begin{tabular}{ccccc}
\hline Line equation & $\mathrm{R}^{2}$ & $\begin{array}{c}\text { Range } \\
(\mathrm{ng} / \mathrm{mL})\end{array}$ & $\begin{array}{c}\text { LOD } \\
(\mathrm{ng} / \mathrm{mL})\end{array}$ & $\begin{array}{c}\text { LOQ } \\
(\mathrm{ng} / \mathrm{mL})\end{array}$ \\
\hline $\mathrm{y}=103.01 \mathrm{x}+32.1$ & 0.9944 & $0.1-150$ & 3.8 & 12.6 \\
\hline
\end{tabular}

resonance (NMR) spectroscopy (Fig. 2(a)). ${ }^{1} \mathrm{H}$ NMR spectrum was obtained using cosolvent of $\mathrm{D}_{2} \mathrm{O}$ and MeOD (1:1) at room temperature.

Accuracy and Precision Tests. Accuracy (recovery), and precision tests of this analytical method were performed against alendronate in rat plasma solution. Rat plasma was collected by centrifugation of blood from a rat. Alendronate/plasma samples were prepared by adding alendronate to plasma at concentrations of 5, 10, 20, $40 \mathrm{ng} /$ $\mathrm{mL}$. Next, the proteins in each sample were removed by adding $3 \mathrm{~mL}$ of $10 \%(\mathrm{w} / \mathrm{v})$ trichloroacetic acid (TCA) to $1 \mathrm{~mL}$ of each sample and by vortexing the samples for $3 \mathrm{~min}$; subsequently, the samples were centrifuged for $15 \mathrm{~min}$ at $6,300 \times \mathrm{g}$ at room temperature. The supernatant

(a)
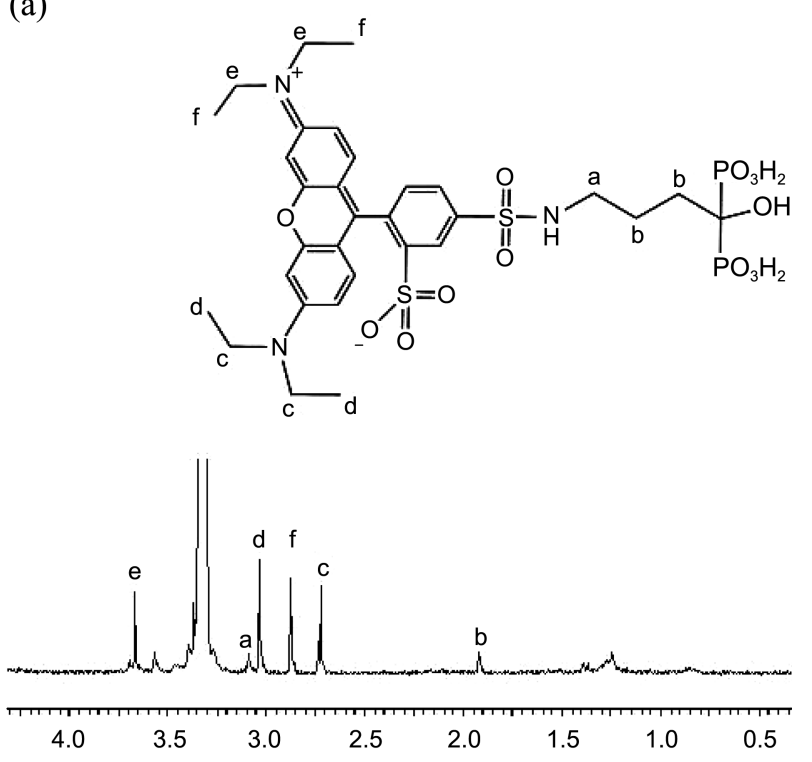

(b)

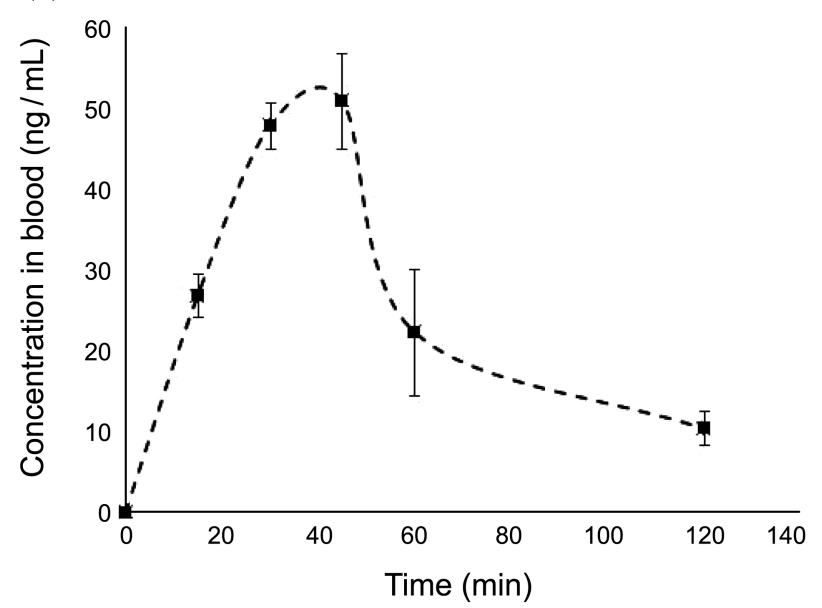

Figure 2. (a) ${ }^{1} \mathrm{H}$ NMR $(300 \mathrm{MHz})$ spectrum of rhodamine $\mathrm{B}$ sulfonyl alendronate (RBSA) in $\mathrm{D}_{2} \mathrm{O}-\mathrm{MeOD}(1: 1)$ cosolvent (b) Profile of time to the mean $(n=3)$ concentration of alendronate in blood of rat after oral administration of $0.3 \mathrm{~mL}$ of $5 \mathrm{mg} / \mathrm{mL}$ alendronate solution. 
Table 2. Accuracy and precision for alendronate in rat plasma. $\operatorname{RSD}(\%$, relative standard deviation $)=$ Deviation/Average $\times 100$

\begin{tabular}{ccccc}
\hline $\begin{array}{c}\text { Mixed (ng/mL) } \\
\text { in rat plasma }\end{array}$ & $\begin{array}{c}\mathrm{n} \\
\text { (No. of test) }\end{array}$ & $\begin{array}{c}\text { Found } \\
(\mathrm{ng} / \mathrm{mL})\end{array}$ & $\begin{array}{c}\text { Recovery } \\
(\%)\end{array}$ & $\begin{array}{c}\text { RSD } \\
(\%)\end{array}$ \\
\hline 5.000 & 10 & 5.074 & 101.4 & 4.911 \\
10.00 & 10 & 9.941 & 99.41 & 4.209 \\
20.00 & 8 & 20.11 & 100.5 & 3.621 \\
40.00 & 8 & 39.90 & 99.97 & 1.110 \\
\hline
\end{tabular}

was transferred to another tube, and $100 \mu \mathrm{L}$ of $1.25 \mathrm{M}$ $\mathrm{CaCl}_{2}$ and $0.4 \mathrm{~mL}$ of $30 \%(\mathrm{w} / \mathrm{v}) \mathrm{NaOH}$ were added to the supernatant to induce precipitation of calcium alendronate(s). The sample was vortexed for $30 \mathrm{~s}$, and then centrifuged for $15 \mathrm{~min}$ at $6,300 \times g$. The supernatant was discarded, and the pellet was washed once in water and dissolved in $0.2 \mathrm{~mL}$ of $0.5 \mathrm{M}$ EDTA-Na $(\mathrm{aq})$ and $0.8 \mathrm{~mL}$ of buffer (sodium carbonate/bicarbonate, $\mathrm{pH} 9$; $0.1 \mathrm{M}$ ). The next step was to induce RBSC conjugation and to perform fluorescence detection in the same way as for the linearity and LOD/LOQ tests above. The results (shown in Table 2) were presented as the mean value of the results of 8 or 10 experiments for each concentrations. The recovery values of alendronate were 99.4$101.4 \%$ with $1.1-4.9 \%$ relative standard deviations (RSDs); this result demonstrates that this method is credible and reproducible.

Efficacy Test of Analysis in Biological Fluid. An in vivo test was performed in rats to confirm the efficacy of pharmacokinetic analysis using this method. The rats were starved for $24 \mathrm{~h}$ and given $10 \mathrm{~mL}$ of water before the test; thereafter, $0.3 \mathrm{~mL}$ of $5 \mathrm{mg} / \mathrm{mL}$ alendronate aqueous solution was orally administered. Blood samples were collected at $15,30,45,60$, and $120 \mathrm{~min} ; 2 \mathrm{~mL}$ blood from 4 rats was collected at each time point. Plasma $(1 \mathrm{~mL})$ was separated from each sample by centrifugation $(10 \mathrm{~min} ; 6,300 \times \mathrm{g}$; $4{ }^{\circ} \mathrm{C}$ ), and procedures to eliminate proteins from the plasma sample, form RBSC-alendronate conjugates, and detect fluorescence were performed; accuracy and precision tests were also conducted.

\section{Results and Discussion}

A linear relationship was obtained between the fluorescence emission and the alendronate concentration over a concentration range of $0.1-150 \mathrm{ng} / \mathrm{mL}$. As shown in Table 1, the $\mathrm{R}^{2}$ value is 0.9944 , which shows that its calibration curve has good linearity for quantitative analysis, and the LOD and LOQ values are $3.8 \mathrm{ng} / \mathrm{mL}$ and $12.6 \mathrm{ng} / \mathrm{mL}$, respectively. The results of accuracy and precision (shown in Table 2) were presented as the mean value of the results of 8 or 10 experiments for each concentrations. The recovery values of alendronate were $99.4-101.4 \%$ with $1.1-4.9 \%$ relative standard deviations (RSDs); this result demonstrates that this method is credible and reproducible. A profile of time and drug concentration in the blood (Fig. 2(b)) was obtained, which indicated that this method can be used in medical and pharmaceutical diagnostics for patients treated with alendronate. This profile showed the concentration $(\mathrm{ng} / \mathrm{mL})$ of alendronate in blood after its oral administration in whole time range, and the maximum concentration was only $53 \mathrm{ng} /$ $\mathrm{mL}$. On the basis of this result, we inferred that NadDPA$2 \mathrm{Zn}^{2+}$ cannot be used for pharmacokinetic (PK) study of alendronate because NadDPA- $2 \mathrm{Zn}^{2+}$ cannot determine concentrations of alendronate lower than its limit of quantitation (LOQ; $0.104 \mu \mathrm{g} / \mathrm{mL}$ ).

The RBSC conjugation method can also be used for PK study because the half-life of alendronate is $>10$ years ${ }^{12}$; further, there is no clear evidence that alendronate is metabolized in humans and animals. This means that alendronate, with its primary amine group, exists stably in blood, and the primary amine of alendronate can be completely conjugated with RBSC.

\section{Conclusions}

The method involving the use of the highly active chromophore, RBSC group, as the conjugation agent is useful for analyzing alendronate, and limit of detection (LOD)/LOQ values suggest that RBSC is about 8 times more sensitive than the FCS NadDPA- $2 \mathrm{Zn}^{2+}$. The efficacy of the FCS method depends on the degree of binding and the binding constant $\left(K_{a}\right)$ because the electrostatic attraction between alendronate and NadDPA- $2 \mathrm{Zn}^{2+}$ is weak. $K_{a}$ is affected by several conditions in the sample solution, such as temperature, $\mathrm{pH}$ and presence of competing molecules. Moreover, the fluorescence sensitivity of NadDPA- $2 \mathrm{Zn}^{2+}$ is not sufficient because of its low extinction coefficient. In contrast, the conjugation between alendronate and RBSC does not have these limitations. Furthermore, higher sensitivity (detection limit, $<1 \mathrm{ng} / \mathrm{mL}$ ) can be expected if a chromophore group with greater fluorescent activity is used for conjugation with alendronate.

\section{References}

1. Shaw, N. J.; Bishop, N. J. Arch. Dis. Child. 2005, 90, 494.

2. Serge, C. L. M.; Cremers; Ruud van Hogezand; Denise Bänffer; Jan den Hartigh; Pieter Vermeij; Socrates E. Papapoulos; Neveen, A. T. Hamdy, Osteoporos Int. 2005, 16, 1727.

3. Mallikarjuna Raoa, B.; Srinivasua, M. K.; Prathima Rania, Ch.; Siva Kumara, S.; Rajender Kumarb, P.; Chandrasekharc, K. B.; Veerender, M. J. Pharm. Biomed. Anal. 2005, 39, 781.

4. Eric, W. T.; Steven, D. C.; Richard, J. F.; Carrie, B.; Dominic, P. I.; Marvin, A. B. J. Pharm. Biomed. Anal. 1994, 12, 983.

5. Quitasol, J.; Krastins, L. J. Chromatogr. A 1994, 671, 273.

6. Hui-Juan, J.; Wei, L.; Kang, Z. Anal. Chim. Acta 2006, 562, 171.

7. De Marco, J. D.; Stephen, E. B.; David, G. R.; Marvin, A. B. J. Pharm. Biomed. Anal. 1989, 7, 1719.

8. Kline, W. F.; Matuszewski, B. K. J. Chromatogr. 1992, 583, 183.

9. Jeong, Y.; Kim, S. Y.; Jin, G-w.; An, S.; Lee, J. H.; Jeong, A-r.; Choi, Y.; Hong, J-I.; Park, J-S. Bull. Korean Chem. Soc. 2010, 31(9), 2561.

10. Hermanson, G. T. Bioconjugate Techniques; 2nd ed.; Academic 
Press: 2008; $\mathrm{p} 421$.

11. Berlman, I. B. Handbook of Fluorescence Spectra of Aromatic Molecules; Academic Press: 1971; p 121.

12. Gertz, B. J.; Holland, S. D.; Kline, W. F.; Matuszewski, B. K.;
Porras, A. G. Osteoporosis Int. 1993, suppl. 3, S13-16.

13. Yun, M-H.; Kwon, K-i. J. Pharm. Biomed. Anal. 2005, 40 168. 